\title{
Kinetic Study \& Statistical Modelling of Sarawak Peat Water Electrocoagulation System using Copper and Aluminium Electrodes
}

\author{
Nazeri Abdul Rahman*, Nurhidayah Kumar Muhammad Firdaus Kumar, Umang Jata Gilan, \\ Elisa Elizebeth Jihed, Adarsh Philip, Allene Albania Linus, Dasima Nen@Shahinan, \\ Verawaty Ismail \\ Department of Chemical Engineering and Energy Sustainability, Faculty of \\ Engineering,Universiti Malaysia Sarawak, Kota Samarahan, Sarawak
}

\begin{abstract}
Minister of Utilities Sarawak, Datuk Seri Dr. Stephen Rundi Utom stated that the coverage of water supply in the rural area is less than 69\% and approximately 114,000 households experienced water shortage problem [1]. Due to insufficient water supply, the residents of the rural and coastal area of Sarawak are often used peat water as daily use for domestic water. The consumption of untreated peat water can lead to various waterborne diseases such as diarrhoea, and other serious illnesses such as typhoid and dysentery. Water treatment system such as electrocoagulation system can be developed to improve the water quality of the peat water as electrocoagulation requires simple equipment that can be operated easily, no usage of chemicals coagulant, producing less sludge and cost-effective treatment system. The main aim of this study is to develop kinetic and statistical modelling for both batch and continuous electrocoagulation processes of peat water treatment in Sarawak using aluminium and copper electrodes. This study focuses on the peat water treatment using electrocoagulation system. The fabricated electrocoagulation system is designed according to the characteristics in which the technology for building and the material used for constructing the electrocoagulation system should be available locally; the electrocoagulation system should be easy to fabricate and maintain, as well as low cost for construction and operation. For this study, Response Surface Methodology in Minitab software and Microsoft Excel are used for kinetic studies, statistical modelling, and process optimization. Process optimization is carried out to minimize energy consumption as well as the turbidity and TSS level. The optimum conditions for batch and continuous electrocoagulation system are $14.899 \mathrm{~A} / \mathrm{m}^{2}$ and $41.818 \mathrm{~min}$, and $3.861 \mathrm{~A} / \mathrm{m}^{2}$ and 37.778 min respectively.
\end{abstract}

Keywords: Peat water, Electrocoagulation, Kinetic study, Statistical modelling, Process optimization

\section{Introduction}

Electrocoagulation is a complex process that involves many chemical and physical phenomena using consumable electrodes for supplying ions into the water stream [2]. Electrocoagulation modelling is suggestively helpful to enhance the design and lessen both equipment and operating costs. Electrocoagulation modelling can predict process performance in a wide range of operational conditions. In most studies of electrocoagulation water treatment, the optimization process has been conducted by manipulating one parameter while other parameters are kept constant at a specific condition [3-5]. This habitual practise of optimization for electrocoagulation process requires numerous

*Nazeri Abdul Rahman. Tel.: +60-82-583332; fax: +60-82-583409/10

E-mail address: arnazeri@unimas.my

Manuscript History:

Received 9 April, 2020, Revised 22 April, 2020, Accepted 23 April, 2020, Published 30 April, 2020

e-ISSN: $2289-7771$

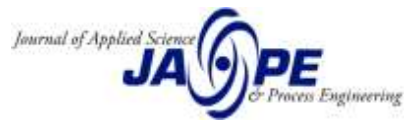


experimental runs and sets of data. Due to disregarding the interactions among the parameters, poor optimization of the process could be resulted, such as underestimation and overestimation on the effect of the electrocoagulation process parameters performances [6].

In Sarawak, $13 \%$ of its total land area is covered with peat which is commonly referred to as peatland. Among the division of Sarawak, Sibu division has the most peatlands which cover $70 \%$ of the division land area in which follow by Sri Aman and Miri with 283,076 hectares and 276,579 hectares respectively [7]. The residents of the rural area are forced to use peat water as daily use of domestic water Due to the water shortage problem. The main concern of the peat water consumption is that the acidic content of the peat water causes the sour taste of the water. Furthermore, the colour of the peat water also distinct and unpleasant. The consumption of untreated peat water can lead to various waterborne diseases such as diarrhoea, and other serious illnesses such as typhoid and dysentery. As such, water treatment system such as electrocoagulation system could be developed effectively and economically to improve the water quality of the peat water. In addition, optimization of the treatment process should be carried out by focusing on the process performances of the system in which an optimization tool can be used to optimize conditions for desirable responses in order to maximize the efficiency of the electrocoagulation system. As such, the main aim of this study is to optimize both batch and continuous electrocoagulation processes of peat water treatment in Sarawak through the formulation of kinetic and statistical models. If both electrocoagulation systems are to be up-scale, batch electrocoagulation system will be utilized as a portable electrocoagulation system for household usage; meanwhile, continuous electrocoagulation system is for a centralized system where residents can collect the water there. In accordance to the aim of this study, the following objectives have been devised, explicitly, (i) to design and fabricate electrocoagulation system using aluminium and copper electrodes for domestic utilization in Sarawak, (ii) to execute a kinetic study on the aluminium and copper electrocoagulation process. (iii) to develop sustainable statistical modelling for electrocoagulation peat water treatment process, and (iv) to optimize the performance and efficiency of the model.

\section{Methodology}

This section mainly describes the methodology for the research project which includes data, and sample collection, design, and fabrication of the electrocoagulation system, kinetic study, and statistical modelling, as well as process optimization.

\subsection{Data sample and collection}

A site visit is conducted to obtain data regarding the water supply problem in Kampung Sebangkoi Jaya, Simunjan, Sarawak. The purpose of the site visit is to develop a better understanding of the issues of clean water shortage experienced by the locals and to propose a solution to overcome the problem. Then, the peat water samples (Figure 1) are collected and stored using the proper apparatus and kept at room temperature in order to maintain the level of contaminant present in the water for further analysis purpose. 


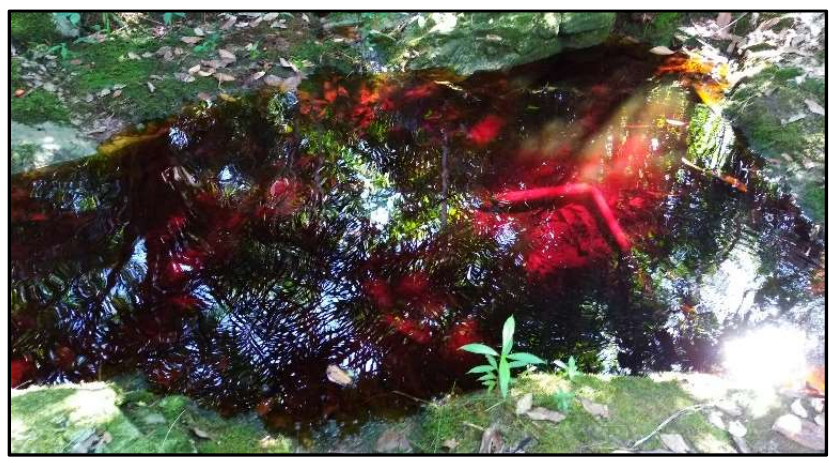

Figure 1. Peat water sample

\subsection{Design and fabrication of electrocoagulation system}

The design of the electrocoagulation process is one of the most crucial aspects of the study. Before designing the electrocoagulation system, research and research on the available design must be performed. Electrocoagulation system usually consists of components such as electrical power supply, sacrificial electrode, stirrer, pump, pre-filter, water filter, and water tank. According to Moussa et al. [8], numerous parameters have to be taken into account in order to increase the efficiency of the electrocoagulation system, as described in Table 1. Based on the parameters in Table 1, the fabrication of the electrocoagulation system can be divided into three main stages, namely material purchasing, dimension specification, and apparatus set-up. The material for electrocoagulation system consists of a DC power supply kit, an aluminium plate electrode, a copper plate electrode, pump, filter media such as gravels, carbon, polypropylene sheet, and microfiber sponge, magnetic stirrer, pipes, and connecting wire. The fabricated electrocoagulation system is designed according to the characteristics as follow:

i. Technology for the electrocoagulation system should be available locally.

ii. The material used for constructing the electrocoagulation system must be available locally.

iii. The electrocoagulation system should be easy to fabricate and maintain.

iv. Low cost for construction and operation.

Table 1. Electrocoagulation System Description [8]

\begin{tabular}{|c|l|}
\hline Parameter & \multicolumn{1}{c|}{ Description } \\
\hline \multirow{3}{*}{ Power supply } & $\begin{array}{l}\text { Three types of power supply which are direct current (DC), alternating } \\
\text { current (AC), as well as alternating pulsed current (APC), are compared. } \\
\text { APC power supply has been proven, resulting in a shorter operating time, } \\
\text { higher removal efficiency and lower operating cost. However, DC power } \\
\text { supply is selected because AC and APC power supply consume higher } \\
\text { power. }\end{array}$ \\
\hline \multirow{5}{*}{ Electrode arrangement } & $\begin{array}{l}\text { Three types of electrode arrangement are compared, which are monopolar- } \\
\text { parallel, monopolar-series and bipolar series. The monopolar-parallel } \\
\text { arrangement is highly preferred due to the highest removal efficiency and } \\
\text { lowest cost. }\end{array}$ \\
\hline Inter-electrode distance & $\begin{array}{l}\text { As the inter-electrode distance increases, the voltage also increases. Thus, } \\
\text { to minimize energy consumption, inter-electrode distance should be } \\
\text { decreased [6]. However, [9] stated that as the inter-electrode distance } \\
\text { increases, the hindrance effects would reduce slowly and results in higher } \\
\text { removal efficiency. }\end{array}$ \\
\hline
\end{tabular}

\subsubsection{Batch electrocoagulation system}


Batch electrocoagulation system is designed and constructed with coagulation, flocculation, and pollutant removal process that happened in situ and can be applied as a portable electrocoagulation system. The electrocoagulation reactor is fabricated from round-shaped plastic material that acts as an electrocoagulation tank where all processes occurred only in the tank. The peat water is pumped into the tank and undergoes electrocoagulation treatment process of reduction and oxidation reaction that formed aluminium hydroxide. The net capacity of the reactor is 13 litres, and aluminium plates are used as electrodes with a dimension of $15 \times 30 \times 0.03 \mathrm{~cm}$. All electrodes are attached to the stainless steel electrode busbar before connecting to a direct current power supply of 0 to 5 Amperes and 0 to 30 Volts. The electrocoagulation tank is supported by an acrylic base holder with a dimension of $20 \times 21 \times 23$ $\mathrm{cm}$. There are two pipes connected to the electrocoagulation tank. The upper pipe act as a treated water pipe that is used to collect treated peat water, and the bottom pipe is for sludge and flocs removal pipe. Fabricated design is shown in Figure 2(a). For batch electrocoagulation system, as the main concern is to design a portable peat water treatment system, the filtration system is not included during the treatment process. The quality of treated peat water can be improved by including a built-in filtration system before collecting the treated water.

\subsubsection{Continuous electrocoagulation system}

The continuous electrocoagulation system is designed consists of five compartments, namely raw water tank, electrochemical cell tank, sludge tank, filter system, and treated water tank. The capacity of the reactor is 7.5 litres with a dimension of $53 \times 20 \times 17 \mathrm{~cm}$. The copper anode and cathode are used as electrodes with a dimension of $15 \times 18.5 \times 0.5 \mathrm{~cm}$. Stainless steel electrode bus bar is used to attach all electrodes before clipped with crocodile wire and connected to a direct current power supply of 0 to 5 Amperes and 0 to 30 Volts. First, peat water is pump into the raw water tank until a certain level before flowing to the electrochemical cell tank. In the electrochemical cell, electrocoagulation takes place; deposition of copper oxide and formation of copper hydroxide. This reaction traps the impurities present in the peat water. The filtration system is for separating the flocs from clean water is made up of several types of filter media such as gravels, carbon, polypropylene sheet, and microfiber sponge. Treated peat water is collected from the outlet valve located at the bottom of the filter tank. In comparison to batch electrocoagulation system, the continuous system is built with a filtration system. Figure 2(b) shows the fabricated design of the treatment system.

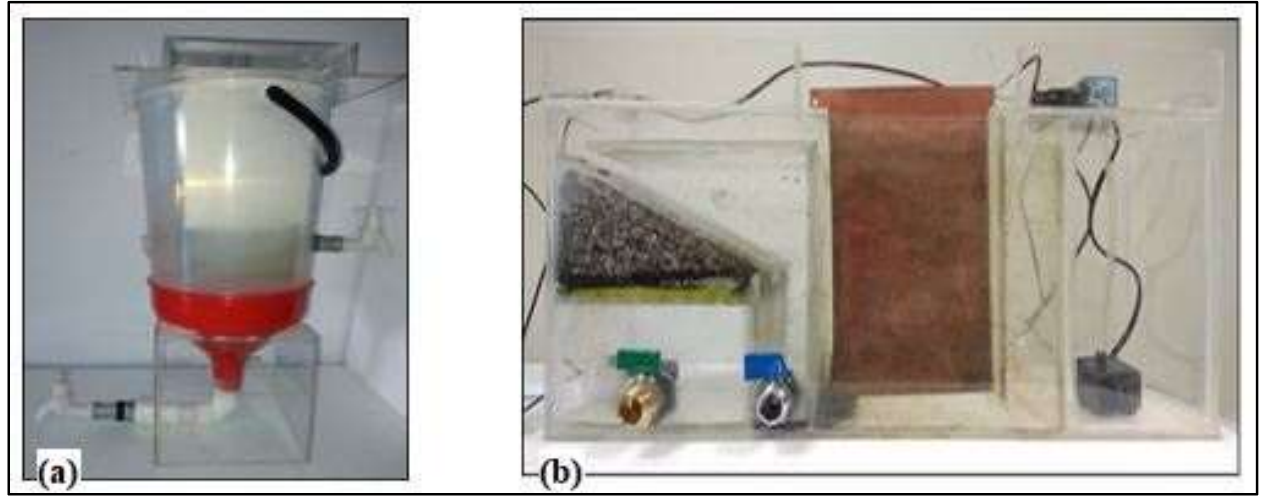

Figure 2. (a) Fabricated Batch System, (b) Continuous System 


\subsection{Kinetic study of Electrocoagulation Process}

For the electrocoagulation system model, the main aspect is the kinetic study on the process. The experiment is conducted based on the experiment condition. All variables are identified before developing the model. The following shows the variables of the electrocoagulation process:

i. Manipulated variables : Number of plate, plate arrangement, residence time and current density.

ii. Responding variables : Removal efficiency (turbidity and total suspended solids).

\subsubsection{Experiment data collection}

Experiments are focusing on reducing the turbidity and total suspended solids (TSS) of the peat water and conducted according to the condition listed in Section 2.3. Treated peat water is analyzed by calculating the removal efficiency of turbidity and total suspended solids (TSS) as shown in Equation 1.

$$
\text { Removal Efficiency }=\frac{C_{o}-C_{i}}{C_{0}}, 100
$$

Where;

$\mathrm{C}_{0}=$ Pollutant concentration before electrocoagulation treatment

$\mathrm{C}_{\mathrm{i}}=$ Pollutant concentration after electrocoagulation treatment

\subsubsection{Amount of metal dissolved}

The sacrificial anode electrode will be oxidized to produce metal ion during the electrocoagulation process. Then, the metal ion will react with hydroxide ion released by cathode electrode, forming a metal hydroxide. The amount of metal dissolved represents the amount of pollutants removed from the water. According to Balasubramanian, et al. [10], the electrode consumption can be estimated according to Faraday's Law, as shown in Equation 2.

$$
w=\frac{I t M}{Z F}
$$

Where;

$\begin{array}{lll}\mathrm{w} & = & \text { Quantity of dissolved electrode material }(\mathrm{g} \text { of } \mathrm{M} / \mathrm{cm} 2) \\ \mathrm{I} & = & \text { Current density }(\mathrm{A} / \mathrm{cm} 2) \\ \mathrm{t} & = & \text { Time }(\mathrm{s}) \\ \mathrm{M} & = & \text { Relative molar mass of the electrode concerned } \\ \mathrm{Z} & = & \text { Number of electrons in oxidation or reduction reaction } \\ \mathrm{F} & = & \text { Faraday's constant }(96500 \mathrm{C} / \mathrm{mol})\end{array}$

\subsubsection{Reaction rate constant}

According to Shafaei et al. [11], the rate of pollutants removal is proportional to the concentration of the pollutant as written in Equation 3. Graph of $\log \mathrm{C} / \mathrm{C}_{0}$ against reaction time can be plotted in order to determine the rate constant value $(\mathrm{k})$, which resulted in a straight line with a negative slope with respect with pollutant concentration. Based on linear equation $y=m x+c$, the gradient, $\mathrm{m}$ of the graph 
can be used to determine the constant rate value. In order to determine the fixed rate constant value, a graph of reaction rate against current density, and reaction time can be plotted.

$$
\log \frac{C}{C_{0}}=-k t
$$

Where;

$$
\begin{array}{lll}
\mathrm{C} & = & \text { Pollutant concentration }(\mathrm{ppm}) \\
\mathrm{C}_{0} & = & \text { Initial pollutant concentration }(\mathrm{ppm}) \\
\mathrm{k} & = & \text { Reaction rate constant } \\
\mathrm{t} & = & \text { Reaction time }
\end{array}
$$

\subsection{Process optimization}

The system efficiency is improved by taking into consideration the parameters related to the electrocoagulation process. For the Sarawak peat water electrocoagulation system and process, Response Surface Methodology in Minitab software is selected for optimization where Central Composite Design (CCD) is selected due to higher efficiency in sequential experiments compared to Box-Behnken Design (BBD) that requires minimum 3 numeric factors while CCD requires 2 to 10 numeric factors. There are five options for the response goals, which are none, minimum, maximum, target, and within the range [17].

\section{Results and discussion}

The section comprises of three main parts; a kinetic study of the electrocoagulation process, statistical modelling, and optimization of the designed electrocoagulation system.

\subsection{Kinetic study of electrocoagulation process}

Metal ion and hydroxide ion are released from anode and cathode during the electrocoagulation process. These ions are then combined together forming metal hydroxide that acts as an absorbent for absorbing the humic substance present in the peat water. The kinetic study of electrocoagulation process involves reaction rate, amount of ion produced and amount of metal dissolved. Experiments were focusing on reducing the turbidity and TSS of the peat water and conducted according to the condition listed in Table 2. The results for turbidity and total suspended solids are measured using DR 900 instrument. The initial value for peat water turbidity and TSS are $16 \mathrm{NTU}$ and $8 \mathrm{mg} / \mathrm{L}$, respectively.

\subsubsection{Kinetic study of batch electrocoagulation process}

Electrocoagulation process for batch system involves in the deposition of the aluminium electrode and flocs formation. The removal efficiency for turbidity and TSS are calculated using Equation 1. Figure 3 shows the effect of the number of the plate on the removal efficiency. A set of experiments are performed with a different number of aluminium plates. Based on the results, as the number of aluminium plate increases, the removal efficiency also increases. Mahvi [12] explained in a study as the number of plate increases; the electricity consumption increases that lead to the increase of flock production consequently causes increasing removal efficiency. Therefore, for the experimental study of electrode distance and current density, the number of plates is fixed to be 8 plates. 


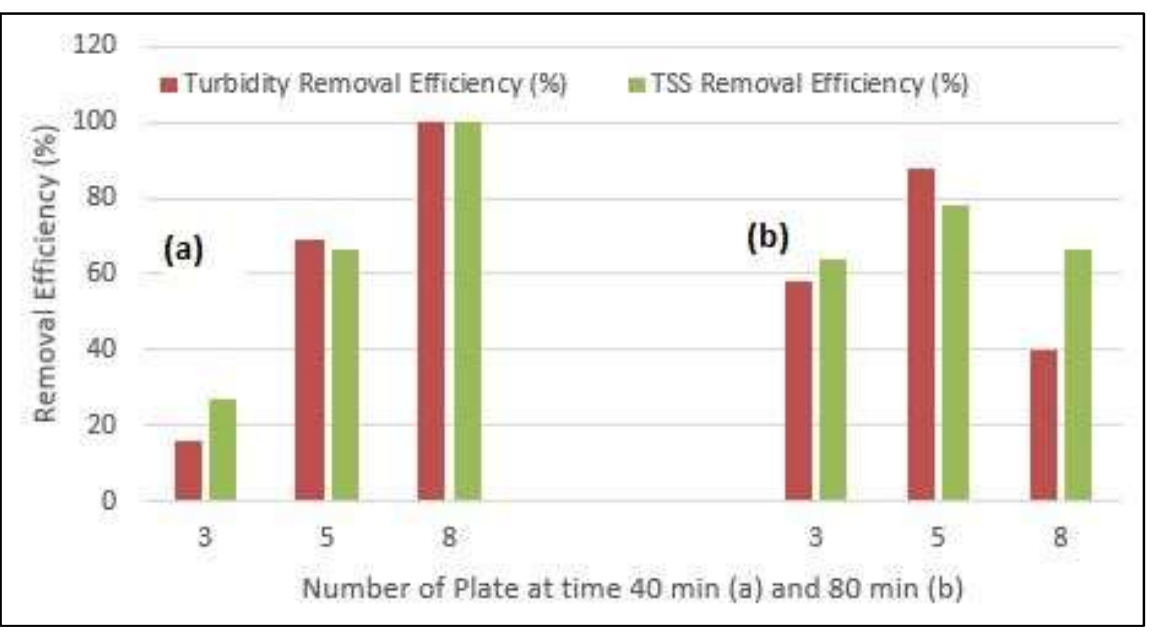

Figure 3. Effect of Number of Plate on Turbidity and TSS Removal Efficiency

Using a constant number of 8 aluminium plates, another series of experiments are carried out with varying the inter-electrode distance. The results obtained in Figure 4 show that the increase in the interelectrode distance leads to an increase in the removal efficiency of turbidity and TSS from $23 \%$ to $100 \%$ and $44 \%$ to $100 \%$ respectively. The results obtained are similar to a study of batch electrocoagulation by Shankar et al. [9] which stated that as the inter-electrode distance increases, the hindrance effects would reduce slowly and results in higher removal efficiency. The statement is supported by Sridhara [13] which specified that the lower the inter-electrode distance, the interaction of colloidal particles and flocs could have a significant impact on the settling and flotation characteristics, resulting in high particles and flocs resistance, resulting in less removal.

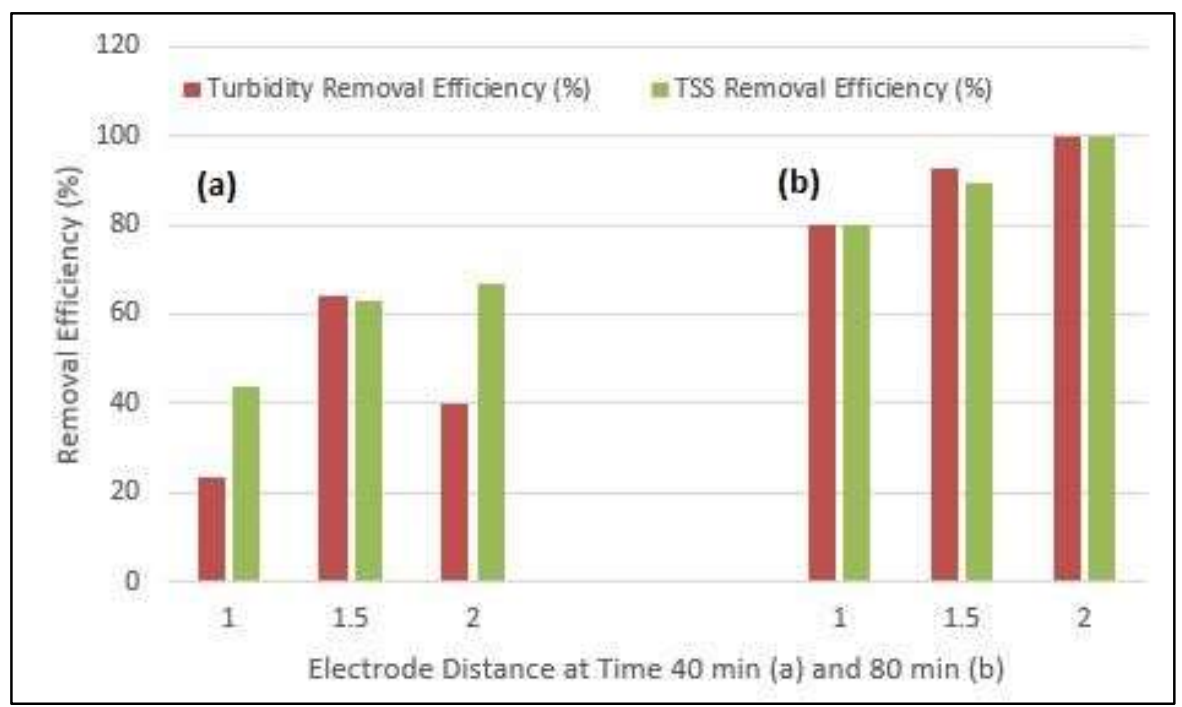

Figure 4. Effect of Electrode Distance on Turbidity and TSS Removal Efficiency 
Effect of current density on turbidity and TSS removal efficiency is conducted with constant electrode distance of $2.0 \mathrm{~cm}$ and 8 aluminium plates. Current density is defined as the ratio of current supply to the total effective area of the anode. As the number of plated are fixed, the effective area of the anode will be constant. Thus, the current density is manipulated by adjusting the current supply. Greater current density leads to greater removal of particles and flocs, as shown in Figure 5. The trends also agreed by a number of researchers Rabiatuladawiyah [14], Kobya [15], Tir and Moulai-Mostefa [16], the higher current density will allow faster treatment of peat water and generate a significant amount of aluminium oxide, results in a greater amount of precipitate for the removal of colloidal particulates.

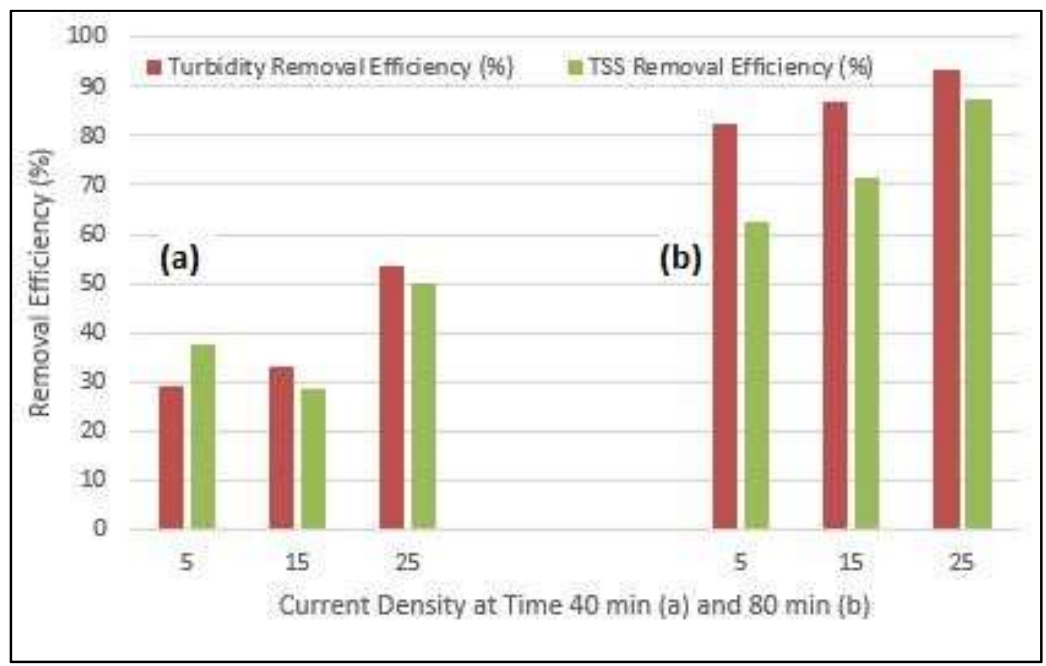

Figure 5. Effect of Current Density on Turbidity and TSS Removal Efficiency

In batch electrocoagulation process, the current density is a crucial parameter as it is the only parameter that can be controlled directly and affecting the rate of reaction within the cell. The reaction rate constant of the electrocoagulation process can be determined from Figure 5 and Equation 3. The gradient of the graph represents the reaction constant of the electrocoagulation process. The reaction is obeying the first-order reaction due to the negative slope shown in Figure 6 and Figure 7, where the trends of the plotted graphs show that as time increases, $\log \mathrm{C} / \mathrm{C}_{0}$ decreases. As the ratio of treated peat water turbidity and TSS level against initial peat water turbidity and TSS level decreased $\left(\log C / C_{0}\right)$, the rate of absorption increased as the treatment time increased. The reaction rate constant is identified from the gradient of the graph. Based on the plotted graph, the reaction rate constant for turbidity is $0.8477 \mathrm{~min}^{-1}$ meanwhile for TSS is $0.6531 \mathrm{~min}^{-1}$. 


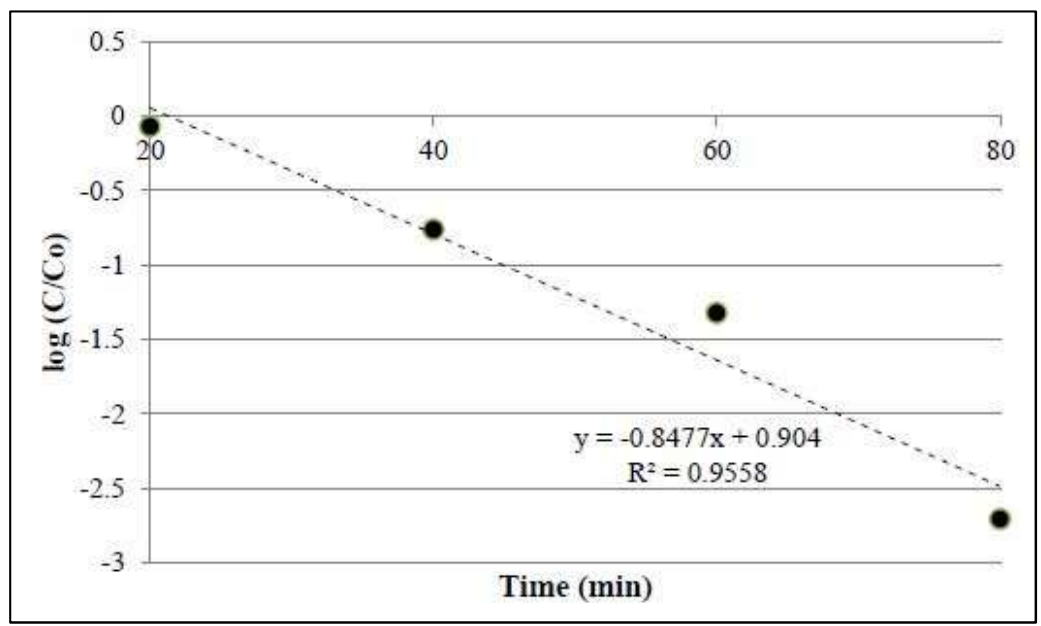

Figure 6. Reaction Rate Constant of Turbidity for Batch System

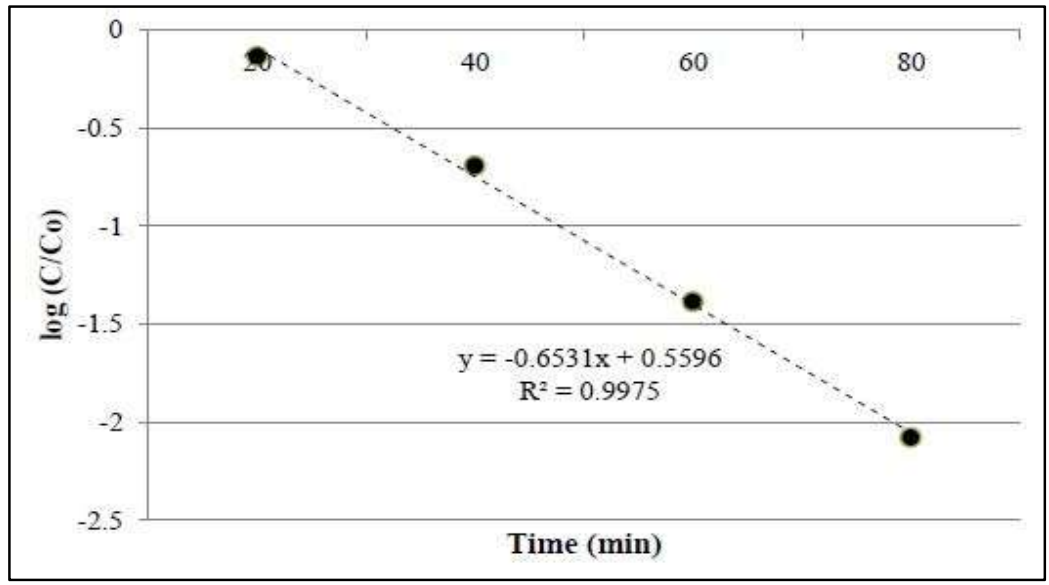

Figure 7. Reaction Rate Constant of TSS Removal for Batch System

Amount of metal dissolved during the redox reaction process represents the amount of pollutants removed from the water. By equating Faraday's Law as in Equation 3, the amount of metal dissolved throughout the electrocoagulation process can be estimated. The amount of aluminium hydroxide ion formed shows an increment when treatment time and current supplied increased. The highest amount of aluminium hydroxide ion formed is at 80 minutes of $2.1474 \mathrm{~g} \mathrm{Al} / \mathrm{cm}^{2}$. Due to electrodissolution from the reaction between current and aluminium plate, the formation of aluminium hydroxide ions rises. Rate of ion released from anode and cathode of aluminium plates affected by the amount of current supply. The greater the current supplied, the greater the energy transferred to the plate. Longer treatment time results in more amount of aluminium hydroxide dissolved from the process. The results achieved are similar to study by Balasubramanian, et al. [10].

\subsubsection{Kinetic study of continuous electrocoagulation process}

For continuous electrocoagulation system, the copper electrode is deposited, and oxides from copper are formed throughout the process. A series of experiments are done with 10,15 and 20 copper 
plates. 20 plates give the highest removal efficiency of turbidity and TSS level of $100 \%$ and $77.78 \%$ respectively as shown in Figure 8. As the number of plate increases, the removal efficiency also increases because higher energy consumption leads to an increase of flock production [12]. Consequently, for the experimental study of inter-electrode distance and current density, the number of plates is fixed to be 20 plates.

To study the effect of inter-electrode distance on the turbidity and TSS removal, another set of experiments are performed by manipulating the inter-electrode distance of $0.7,1.0$, and $1.5 \mathrm{~cm}$. The results obtained from the experimental study show that the highest removal efficiency is achieved with the smallest inter-electrode distance. At the electrode distance of $0.7 \mathrm{~cm}$, the removal efficiency for turbidity and TSS are $84.21 \%$ and $83.33 \%$ respectively, as presented in Figure 9. Using a fixed distance of $0.7 \mathrm{~cm}$ for inter-electrode distance and 20 copper plates, the effect of current density on the turbidity and TSS removal efficiency is carried out by varying the current applied of 1,3 , and $5 \mathrm{~A}$. As expected, after a given time, the removal efficiency increased with increase in current density. The maximum turbidity and TSS removals are $90.91 \%$ and $100 \%$ respectively, with the highest current density of 5.99 $\mathrm{A} / \mathrm{m}^{2}$. Takdastan [17] quoted that as higher the current is supplied, the greater the amount of copper oxides is formed in which resulting in an increased in the amount of pollutants removal.

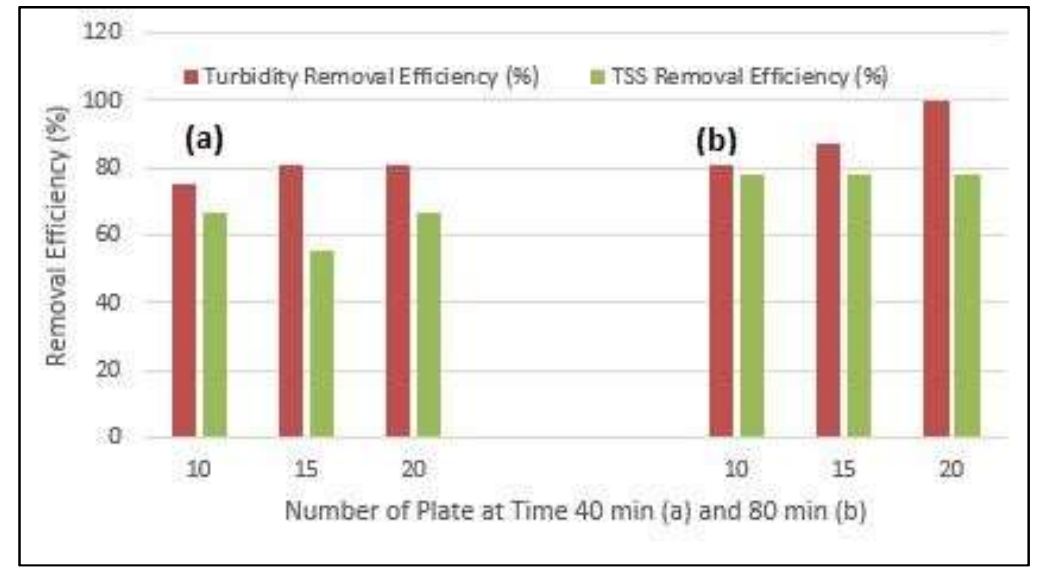

Figure 8. Effect of Number of Plate on Turbidity and TSS Removal Efficiency

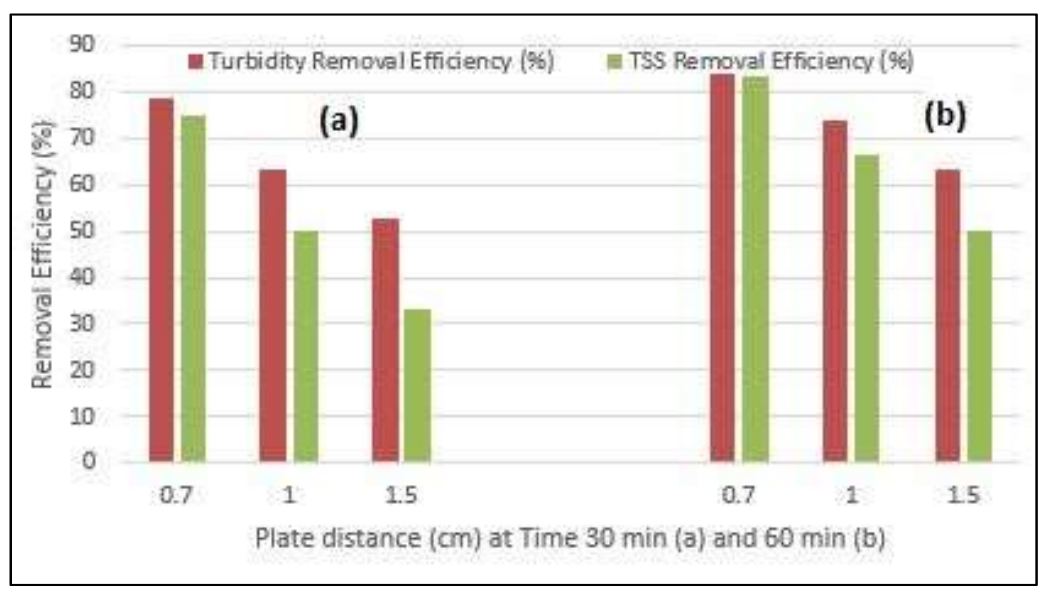

Figure 9. Effect of Plate Distance on Turbidity and TSS Removal Efficiency 


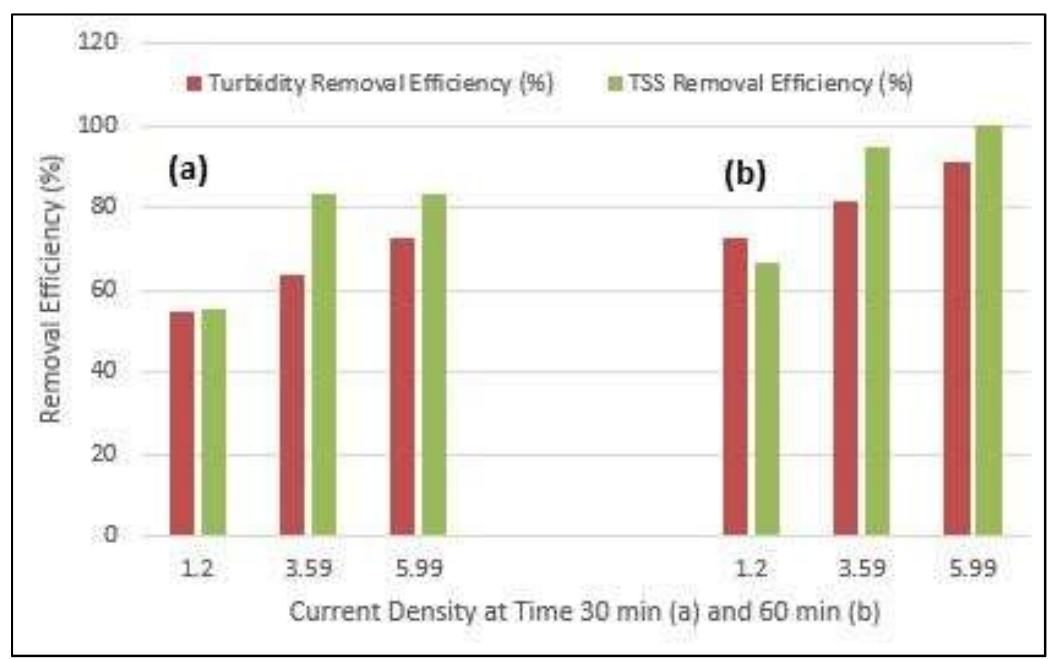

Figure 10. Effect of Current Density on Turbidity and TSS Removal Efficiency

Graph of $\log \mathrm{C} / \mathrm{C} 0$ versus time is plotted to identify the reaction constant of the process, where the gradient of the graph represents the reaction constant of the electrocoagulation process. Figure 11 and Figure 12 show the reaction rate constant for turbidity and TSS, respectively. The increment of time leads to a decrease in $\log \mathrm{C} / \mathrm{C} 0$. The rate of absorption increased, as the ratio of treated peat water turbidity and TSS level against initial peat water turbidity and TSS level $(\log \mathrm{C} / \mathrm{C} 0)$ decreased, with an increase in the treatment time. The reaction rate constant is identified from the gradient of the graph. The reaction rate constant for turbidity is $0.3167 \mathrm{~min}^{-1}$ meanwhile for TSS is $0.1245 \mathrm{~min}^{-1}$.

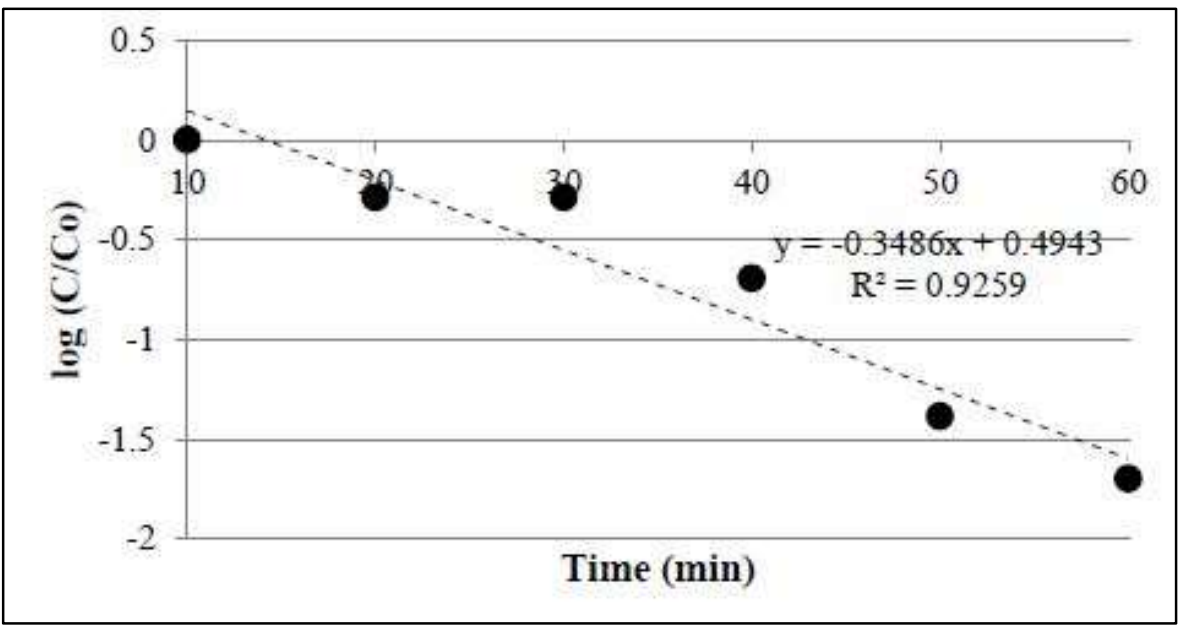

Figure 11. Reaction Rate Constant of Turbidity for Continuous System 


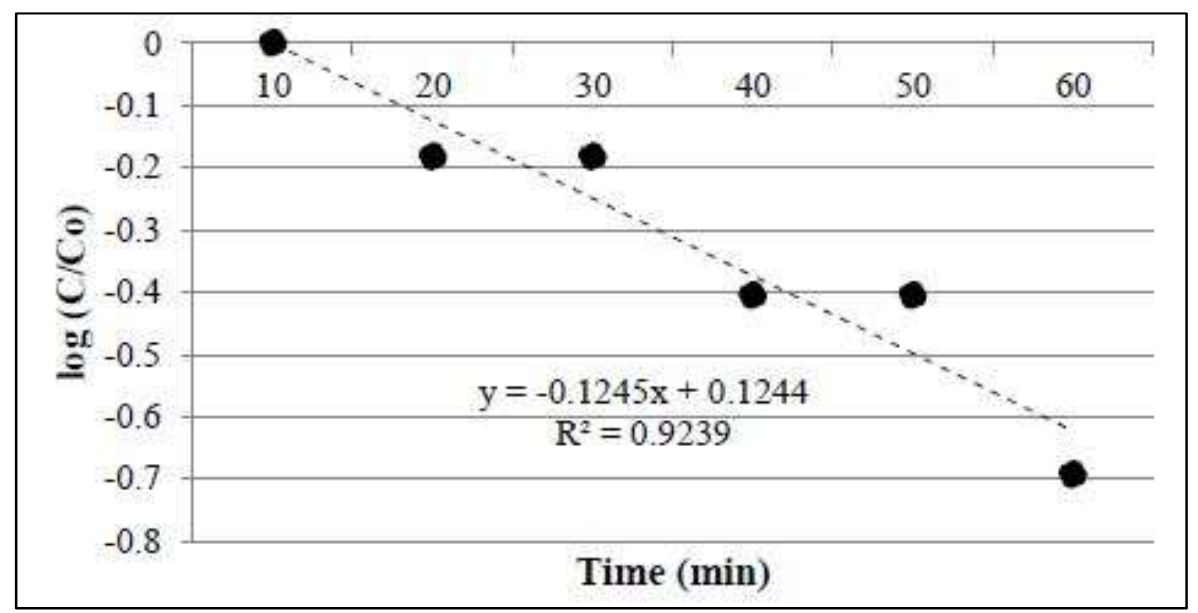

Figure 12. Reaction Rate Constant of TSS Removal for Continuous System

\subsection{Statistical modelling of electrocoagulation process}

An empirical model for electrocoagulation treatment process is developed by conducting a series of experiment to obtain the desired experimental output data. Minitab software is used for designing the experiment where CCD is chosen from Response Surface Methodology (RSM) as CCD is highly useful in sequential experiments.

\subsubsection{Batch electrocoagulation process}

Design of experiment for batch electrocoagulation process is developed by entering two independent variables which are current density and time. The range for current density is 5 to $25 \mathrm{~A} / \mathrm{m}^{2}$ while the range for time is 20 to $60 \mathrm{~min}$. Table 2 presented the results of modelled turbidity (NTU) and TSS (mg/L). The turbidity is in the range of 16.41 to $1.98 \mathrm{NTU}$; meanwhile, for TSS, the level is in the range of 2.91 to $6.99 \mathrm{mg} / \mathrm{L}$. Equation 4 and Equation 5 is the quadratic equations developed from the design of the experiment. The developed equations is then undergone statistical analysis to determine the validity and accuracy of the model using analysis of variance (ANOVA). The ANOVA results of quadratic models for batch electrocoagulation system are tabulated in Table 9. Fisher test is used to evaluate the significance and interaction of each factor.

According to Montgomery Montgomery [18], the model terms are significant if the F-value less than 0.05 and coefficients with P-value greater than 0.100 are considered statistically insignificant. From Table 3, the P-value of the model for turbidity is slightly higher than 0.05 . However, the model is still acceptable as the overall model meet the significant requirement. The P-value can be improved by repeating the experiments with a narrow variable range. For instance, the range for the current density of the batch electrocoagulation system is from 5 to $25 \mathrm{~A} / \mathrm{m}^{2}$. Due to the smaller effective anode area, the current density is larger. By increasing the effective anode area, a smaller range of current density can be obtained. 
Table 2. Design of Experiment for Batch Electrocoagulation Process Modelling

\begin{tabular}{|c|c|c|c|c|}
\hline Run & $\begin{array}{c}\text { Current Density } \\
\left(\mathbf{A} / \mathbf{m}^{\mathbf{2}}\right)\end{array}$ & $\begin{array}{c}\text { Time } \\
\mathbf{( m i n )}\end{array}$ & Turbidity (NTU) & TSS (mg/L) \\
\hline 1 & 5 & 20 & 16.41 & 2.91 \\
\hline 2 & 25 & 20 & 15.57 & 3.07 \\
\hline 3 & 5 & 60 & 11.38 & 4.91 \\
\hline 4 & 25 & 60 & 13.54 & 6.07 \\
\hline 5 & 5 & 40 & 5.145 & 4.16 \\
\hline 6 & 25 & 40 & 5.81 & 4.82 \\
\hline 7 & 15 & 20 & 1.99 & 6.99 \\
\hline
\end{tabular}

$$
\begin{gathered}
\text { Turbidity }=63.25-4.317 A+0.1400 A^{2}+0.02187 B^{2}+0.0037 A B \\
T S S=-3.75+1.183 A+0.0937 B-0.04000 A^{2}-0.000625 B^{2}+0.001250 A B
\end{gathered}
$$

Where;

$$
\begin{array}{lll}
\mathrm{A} & = & \text { Current Density } \\
\mathrm{B} & = & \text { Time }
\end{array}
$$

Coefficient of determination, as presented in Table 9 is an important aspect in performing the modelling that can determine the parameter for the overall efficiency of the model prediction. The coefficient of determination of turbidity for batch electrocoagulation system shows a high value of Rsquared, which is 0.979 . Higher R-squared value ensures a good correlation between experimental values with predicted values of the model. Furthermore, R-squared value should be in a reasonable agreement with adjusted R-squared value. Montgomery [18] added, if the R-squared and adjusted Rsquared value differ reasonably, there is a potential that insignificant terms have been included in the model. Adjusted R-squared is the R-squared value that has been modified based on the number of predictors. When new independent variable is added to the model, if there is an increment in the value of R-squared, the new added independent variable affects the model and should be considered during the modelling in order to obtain a more variability model. Generally, R-squared value is higher compared to the adjusted R-squared value. Based on Table 9, the adjusted R-squared value is less than the R-squared value. Hence, the experimental data is significant and fit to the model.

Table 3. Analysis of Variance on Turbidity

\begin{tabular}{|c|c|c|c|c|c|}
\hline Source & $\begin{array}{c}\text { Degree of } \\
\text { Freedom }\end{array}$ & $\begin{array}{c}\text { Sum of } \\
\text { Squares }\end{array}$ & $\begin{array}{c}\text { Mean } \\
\text { Squares }\end{array}$ & F-Value & P-Value \\
\hline Model & 5.000 & 191.197 & 38.383 & 9.400 & 0.062 \\
\hline Error & 4.083 & 4.083 & - & - & - \\
\hline \multicolumn{3}{|c|}{ Turbidity Coefficient of Determination } \\
\hline \multicolumn{3}{|c|}{ Value (\%) } \\
\hline Rodel Summary & \multicolumn{3}{c|}{97.92} \\
\hline Adjusted R-Squared & & \\
\hline
\end{tabular}

Basically, the modelling method for TSS is similar with turbidity equation development. The ANOVA study for the TSS value of batch electrocoagulation system obtained from Response Surface Methodology. F-value of 32.030 and P-value of 0.033 show a significant result for turbidity indicates that the experimental data fits the quadratic model as developed in Equation 5. The R-squared value 
obtained is high, which is 0.994 and the adjusted R-squared value is lower than the R-squared value. Thus, the data is said to be fit to the developed model.

\subsubsection{Continuous electrocoagulation process}

Similarly, continuous electrocoagulation process is developed using Central Composite Design (CCD) from the Response Surface Methodology (RSM). By entering two independent variables; current density and time, design of the experiment is developed with the response to turbidity and TSS level of the peat water. The range for current density and time is 1.20 to $5.99 \mathrm{~A} / \mathrm{m}^{2}$ and 20 to 60 min respectively. The results of modelled turbidity (NTU) and TSS $(\mathrm{mg} / \mathrm{L})$ are tabulated in Table 4 . The range of turbidity is 4.02 to $8.01 \mathrm{NTU}$, while TSS is the range of 3.17 to $5.75 \mathrm{mg} / \mathrm{L}$. Equation 6 and Equation 7 are the quadratic equations developed from the design of the experiment. The developed equations are then undergone statistical analysis to determine the validity and accuracy of the model using analysis of variance (ANOVA). The ANOVA results of quadratic models for batch electrocoagulation system are presented in Table 4.

The P-value is said to be significant if it is lower than 0.05 , with $95 \%$ confidence interval. From Table 5, the P-value is 0.001 , which is lower than 0.05 . Thus, the model is significant. The lack of fit compares the residual error to the pure error from the central points in the experimental design points. Therefore, the lack of fit should be insignificant [19]. The ANOVA results in Table 5 show that P-value for lack of fit is higher than 0.05 , leading to an insignificant lack of fit. Coefficient of determination, as represented in Table 5 shows a high R-squared value of 0.933 . The adjusted $\mathrm{R}$-squared value is 0.885 shows a reasonable agreement with R-squared value. For continuous system, predicted R-squared value determines the response for the new predictors. Similar to adjusted R-squared, predicted R-squared value usually less than R-squared value. Based on Table 5, both values of adjusted and predicted Rsquared are lower than R-squared. Thus, the experimental data is significant and fit to the model.

Table 4. Design of Experiment for Continuous Electrocoagulation Process Modelling

\begin{tabular}{|c|c|c|c|c|}
\hline Run & $\begin{array}{c}\text { Current Density } \\
\left(\mathbf{A} / \mathbf{m}^{\mathbf{2}}\right)\end{array}$ & $\begin{array}{c}\text { Time } \\
(\mathbf{m i n})\end{array}$ & $\begin{array}{c}\text { Turbidity } \\
(\mathbf{N T U})\end{array}$ & $\begin{array}{c}\text { TSS } \\
(\mathbf{m g} / \mathbf{L})\end{array}$ \\
\hline 1 & 1.20 & 10 & 8.01 & 5.75 \\
\hline 2 & 5.99 & 10 & 8.01 & 4.74 \\
\hline 3 & 1.20 & 60 & 8.01 & 5.08 \\
\hline 4 & 5.99 & 60 & 8.01 & 4.07 \\
\hline 5 & 1.20 & 35 & 8.01 & 4.17 \\
\hline 6 & 5.99 & 35 & 5.67 & 3.17 \\
\hline 7 & 3.60 & 10 & 4.02 & 4.50 \\
\hline
\end{tabular}

$$
\begin{gathered}
\text { Turbidity }=-4.57+4.576 A+0.2416 B-0.697 A^{2}-0.004 B^{2}+0.01253 A B \\
T S S=8.25-1.138 A+0.2416 B-0.697 A^{2}+0.001986 B^{2}+0.00000 A B
\end{gathered}
$$

Where;
$\mathrm{A}=$
Current Density
$\mathrm{B}=$ Time 
Table 5. ANOVA Study on Turbidity

\begin{tabular}{|c|c|c|c|c|c|}
\hline Source & $\begin{array}{c}\text { Degree of } \\
\text { Freedom }\end{array}$ & $\begin{array}{c}\text { Sum of } \\
\text { Squares }\end{array}$ & $\begin{array}{c}\text { Mean } \\
\text { Squares }\end{array}$ & F-Value & P-Value \\
\hline Model & 5 & 98.917 & 19.783 & 19.55 & 0.001 \\
\hline Lack of Fit & 3 & 4.283 & 1.428 & 2.04 & 0.251 \\
\hline Pure Error & 4 & 2.800 & 0.700 & - & - \\
\hline \multicolumn{6}{|c|}{ Turbidity Coefficient of Determination } \\
\hline \multicolumn{4}{|c|}{93.32} \\
\hline Model Summary & \multicolumn{3}{c|}{88.54} \\
\hline Rdjusted R-Squared & 59.60 \\
\hline
\end{tabular}

Based on the designed experiment for TSS, quadratic equation is developed as in Equation 7. The ANOVA study for the TSS value of continuous electrocoagulation system obtained from Response Surface Methodology. Fisher test is done and obtained P-value of 0.016 that show a significant result for TSS indicates that the experimental data fits the quadratic model. The R-squared value obtained is high, which is 0.817 and the adjusted R-squared value is lower than the R-squared value of 0.686 . Predicted R-squared can be used to determine the predictions of new predictors. The value for predicted R-squared of TSS is 0.453 . Both value of adjusted and predicted R-squared are lower than R-squared. Thus, the experimental data is significant and fit to the developed model. For the lack of fit test, as the $\mathrm{P}$-value of 0.801 is higher than 0.05 , the lack of fit is not statistically significant, which means the test does not detect any lack of fit.

\subsection{Results comparison between modelling and experimental}

Comparison of modelling and experimental results is performed to ensure the validity of the modelled equation for turbidity and TSS. Comparison is made by determining the deviation between modelling and experimental results.

\subsubsection{Results comparison for batch electrocoagulation process}

The experimental results are obtained from the kinetic study of electrocoagulation treatment process while modelling results are obtained from the modelled equation of Equation 4 and Equation 5. The highest experimental value for turbidity and TSS are 17 NTU and $7 \mathrm{mg} / \mathrm{L}$, respectively. For modelling, the highest value for turbidity is 16.41 NTU and for TSS is $6.99 \mathrm{mg} / \mathrm{L}$. The deviation of both results shows that the highest deviation for turbidity is $28.68 \%$ and $4.08 \%$ for TSS at the condition of 5 $\mathrm{A} / \mathrm{m}^{2}$ and $40 \mathrm{~min}$. There are few factors that lead to huge deviation of the results, such as the accuracy of the experimental results. During the experiments, there might be unnoticed error occurred. For instance, the water level for electrocoagulation tank of the batch system is filled up to 8 litres only. Lower volumes of water affect the effective area of the anode, which results in higher current density. Additionally, higher current density results in a higher range for the input parameter of the modelling equation. This leads to a larger variance of the experimental data. Repeating the experiments with narrow variable range can reduce the variability of the data.

\subsubsection{Results comparison for continuous electrocoagulation process}

The experimental results are obtained from the experiments of electrocoagulation treatment process, whereas the modelling results are equated from Equation 6 and Equation 7. The highest experimental value for turbidity and TSS are $9 \mathrm{NTU}$ and $6 \mathrm{mg} / \mathrm{L}$, respectively. For modelling, the highest value for turbidity is $8.00 \mathrm{NTU}$ and for TSS is $5.75 \mathrm{mg} / \mathrm{L}$. The deviation of both results shows that the highest deviation for turbidity is $14.36 \%$ at the condition of $1.2 \mathrm{~A} / \mathrm{m}^{2}$ and $60 \mathrm{~min}$ and $12.58 \%$ 
for TSS at the condition of $3.59 \mathrm{~A} / \mathrm{m}^{2}$ and $10 \mathrm{~min}$. The higher deviation of both results might be due to experimental error. For continuous electrocoagulation system, there is a filter system before collecting the treated peat water sample. However, the filter system is not functioning well. The filter medium is not secured properly causing the gravels to fall to the treated water tank. This might affect the quality of the treated water. Hence, contribute to the deviation of the results for both experimental and modelling.

\subsection{Optimization of electrocoagulation system}

Optimization of the electrocoagulation system is performed by controlling the variables using Response Optimizer provided by Response Surface Methodology. In order to determine the optimum condition for the electrocoagulation system in terms of current density and time, the goals for the response of turbidity and TSS is minimized.

\subsubsection{Optimization of batch electrocoagulation system}

The response optimization is set to be minimum in order to minimize the turbidity and TSS level of the peat water. The target for turbidity and TSS of 3 NTU and $2 \mathrm{mg} / \mathrm{L}$ is auto-generated by the Response Optimizer. Based on Figure 2(a), the optimum condition for batch electrocoagulation system is at current density $14.899 \mathrm{~A} / \mathrm{m}^{2}$ and at time $41.818 \mathrm{~min}$. At the optimum condition, the minimum turbidity level is $-8.5894 \mathrm{NTU}$, and TSS level is $0.9697 \mathrm{mg} / \mathrm{L}$. The composite desirability evaluates the effectiveness of the combination of variables that satisfied the target that has been set by the response. The composite desirability for batch electrocoagulation is 1 . The value indicates that the setting had achieved favourable results for all responses as a whole. Similarly, the individual desirability, $\mathrm{d}$ for both turbidity and TSS show the same value.

\subsubsection{Optimization of continuous electrocoagulation system}

In order to minimize the turbidity and TSS level of the peat water, the response optimization is set to be minimum. The target for turbidity is 2 NTU, and TSS is $1 \mathrm{mg} / \mathrm{L}$ is auto-generated by the Response Optimizer. The optimum condition for continuous electrocoagulation system is at current density $3.8611 \mathrm{~A} / \mathrm{m}^{2}$ and at the time, $37.7778 \mathrm{~min}$ as displayed in Figure 13(b). At the optimum condition, the minimum turbidity level is $2.0247 \mathrm{NTU}$, and TSS level is $2.8629 \mathrm{mg} / \mathrm{L}$. The composite desirability evaluates the effectiveness of the combination of variables that satisfied the target that has been set by the response. The composite desirability for continuous electrocoagulation is 0.8269 , which is close to 1 as shown in Figure 13(b). The value indicates that the setting had achieved favourable results for all responses as a whole. However, the individual desirability, $\mathrm{d}$ for both turbidity and TSS show different values. The desirability of turbidity is slightly higher compared to TSS. This shows that the response for turbidity is more important than TSS and the composite desirability. To obtain higher individual desirability for higher yield, the setting can be adjusted using optimization plot. 


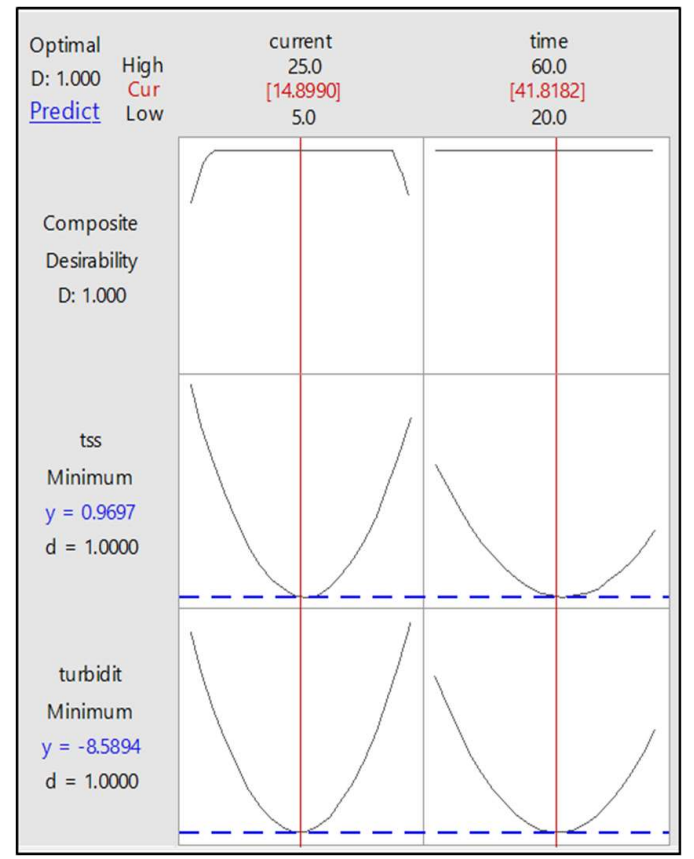

Figure 13(a). Optimization Plot for Batch Electrocoagulation System

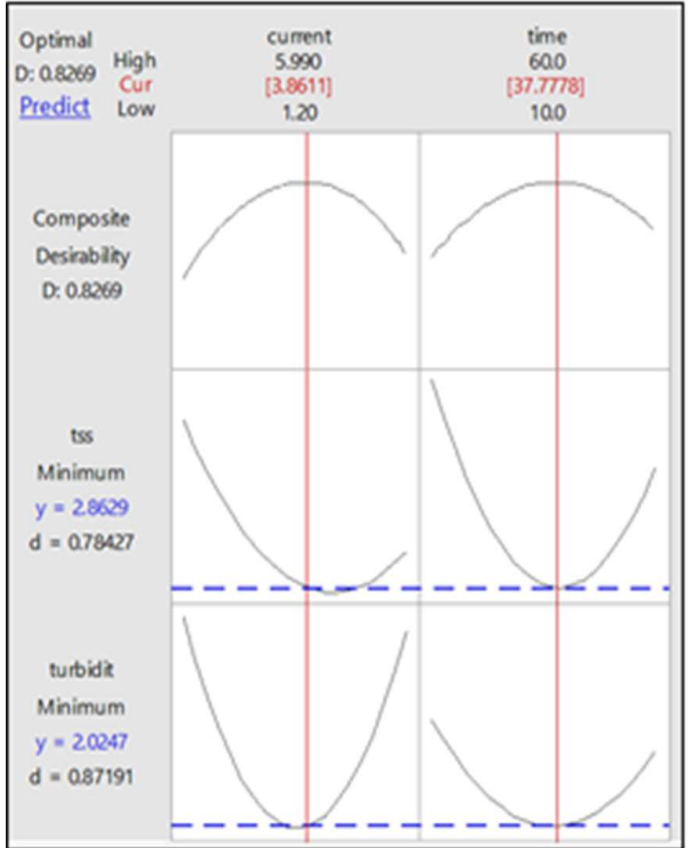

Figure 13(b). Optimization Plot for Batch Electrocoagulation System

\section{Conclusion}

The aim of the study is to develop a kinetic study and statistical modelling for electrocoagulation process of peat water treatment in Sarawak. Corresponding to the aim, there are a number of objectives that have been achieved. Firstly, batch and continuous electrocoagulation treatment system are designed and fabricated using different types of electrodes which are aluminium and copper. Batch system only consists of an electrocoagulation tank, where all process occurred in situ. Whereas, the continuous system is divided into several parts of raw peat water tank, electrochemical cell tank, sludge tank, filter system and treated water tank. Besides, kinetic study for batch and continuous electrocoagulation system is executed and analyzed. The experiments are performed by manipulating the number of the electrode, the inter-electrode distance and the current density. The reaction rate of the electrocoagulation process is determined by varying the current density and treatment time. In addition, the maximum amount of aluminium hydroxide ion and copper hydroxide ion produced is estimated to be $2.1474 \mathrm{~g} \mathrm{Al} /$ $\mathrm{cm}^{2}$ and $3.5559 \mathrm{~g} \mathrm{Cu} / \mathrm{cm}^{2}$, respectively. Furthermore, the statistical modelling for batch and continuous electrocoagulation process is developed. By using Response Surface Methodology; Central Composite Design from Minitab software, design of experiments is performed. Quadratic equations are developed and analyzed using ANOVA to determine the fitness of the data to the modelled equation. Lastly, the electrocoagulation system is optimized by minimizing the turbidity and TSS level of the peat water using Response Optimizer option in RSM. The optimum condition for current density and time for batch and the continuous system is $14.899 \mathrm{~A} / \mathrm{m}^{2}$ and $41.818 \mathrm{~min}$, and $3.861 \mathrm{~A} / \mathrm{m}^{2}$ and $37.778 \mathrm{~min}$ respectively.

\section{Acknowledgements}

The author wishes to express their profound sense of gratitude to the Department of Chemical Engineering and Energy Sustainability, Faculty of Engineering, Universiti Malaysia Sarawak. 


\section{References}

[1] Ogilvy, G. (2017). Sarawak set to kick off programme to supply water to rural areas, in The Star Online, ed. Kuching.

[2] Mollah, M.Y.A., Morkovsky, P., Gomes, J.A.G., Kesmez, M., Parga, J. and Cocke, D. L.(2004). Fundamentals, Present and Future Perspectives of Electrocoagulation, Journal of Hazardous Materials, Vol. 114, No. 1-3, 199-210.

[3] Abuzaid, N.S.,Bukhari, A.A. and Al-Hamouz, Z.M. (2002). Ground Water Coagulation Using Soluble Stainless Steel Electrodes, Advances in Environmental Research, Vol. 6, No. 3, 325-333, 2002.

[4] Koparal, A.S. and Ogutveren, U.B. (2002). Removal of Nitrate from Water by Electroreduction and Electrocoagulation, Journal of Hazardous Materials, Vol. 89, 83-94.

[5] Kumar, P.R., Chaudhari, S., Khilar, K.C. and Mahajan, S.P. (2004). Removal of Arsenic from Water by Electrocoagulation, Chemosphere, Vol. 55, No. 9, 1245-1252.

[6] Hakizimana, J.N., Gourich, B., Chafi, M., Stiriba, Y., Vial, C., Droguir, P. and Naja, J. (2017). Electrocoagulation Process in Water Treatment: A Review of Electrocoagulation Modeling Approaches, Desalination, Vol. 404, 1-21.

[7] Sa'don, N.M. and Abdul Karim, A.R. W. Jaol, and W. H. Wan Lili, (2014). Sarawak Peat Characteristics and Heat Treatment, UNIMAS e-Journal of Civil Engineering, Vol. 5, No. 3, 6 - 12.

[8] Moussa, D.T., El-Naas,M.H. and Al-Marri, M.J. (2017). A Comprehensive Review of Electrocoagulation for Water Treatment: Potentials and Challenges, Journal of Environmental Management, Vol. 186, 24-41.

[9] Shankar, R., Singh, L., Mondal, P. and Chand, S. (2013). Removal of COD, TOC, and Color from Pulp and Paper Industry Wastewater through Electrocoagulation, 7711-7722.

[10] Balasubramanian, N., Kojima,T. and Srinivasakannan, C. (2009). Arsenic Removal through Electrocoagulation: Kinetic and Statistical Modeling, Chemical Engineering Journal, Vol. 155, No. 1, 7682.

[11] Shafaei, A., Pajootan, E., Nikazar, M. and Arami, M. (2011). Removal of Co (II) from aqueous Solution by Electrocoagulation Process Using Aluminum Electrodes, Desalination, Vol. 279, 121-126.

[12] Mahvi, A.H., Bazrafshan. E., Mesdaghinia, A.R., Naseri, S., and Vaezi, F., (2007). Chromium (Cr) Removal from Aqueous Environments by Electrocoagulation Process Using Aluminum Electrodes, Journal Of Water and Wastewater, Vol. 62, 28-34.

[13] Sidhara, R., Sivakumarb, V., Prince Immanuelc, V., and Maranb, P. J., (2011). Treatment of Pulp and Paper Industry Bleaching Effluent by Electrocoagulant Process, J. Hazard. Mater, Vol. 186, 1495-1502.

[14] Rabiatuladawiyah, D., Luqman, C.A. and Shafreeza, S. (2017). Potential of Copper Electrodes in Electrocoagulation Process for Glyphosate Herbicide Removal, MATEC Web of Conferences, Vol. 103, No. 06019 .

[15] Kobya, M., Demirbas, E., Dedeli, A., and Sensoy, M. T. (2010). Treatment of Rinse Water from Zinc Phosphate Coating by Batch and Continuous Electrocoagulation Processes, J. Hazard. Mater, Vol. 173, No. 1-3, 326-334.

[16] Tir M. and Moulai-Mostefa, N. (2008). Optimization of Oil Removal from Oily Wastewater by Electrocoagulation Using Response Surface Method, Journal of Hazardous Materials, Vol. 158, No. 1, $107-$ 115.

[17] Takdastan, A., Tabar, S.E., Islam, A., Bazafkan, M.H. and Naisi, A.K. (2015). The Effect of the Electrode in Fluoride Removal from Drinking Water by Electro Coagulation Process, International Conference on Chemical, Environmental and Biological Sciences.

[18] Montgomery, D.C. (2010). Design and Analysis of Experiments, seven ed. New Delhi: Wiley India Pvt. Ltd.

[19] Makwana, A.R. and Ahammed, M. M. (2016). Continuous Electrocoagulation Process For The PostTreatment Of Anaerobically Treated Municipal Wastewater, Process Safety and Environmental Protection, Vol. 102, 724-733, 2016. 